\title{
Construction of Water Absorbing Pavements by using Asphalt
}

\author{
Mr. Nikhil Mishra \\ Dept of Civil Engineering \\ J D College of Engineering and Management, \\ Nagpur. \\ Mr. Sujit Akare \\ Dept of Civil Engineering \\ J D College of Engineering and Management, \\ Nagpur.
}

\author{
Mr. Ashish Sakharwade \\ Dept of Civil Engineering \\ J D College of Engineering and Management, \\ Nagpur. \\ Mrs. Shivani Tadam \\ Dept of Civil Engineering \\ J D College of Engineering and Management, \\ Nagpur.
}

\author{
Prof. Nilesh Pal \\ Under Guidance: \\ Dept of Civil Engineering \\ J D College of Engineering and Management, Nagpur.
}

\begin{abstract}
Now a days not only India but whole world are suffering from rising temperature, plastic waste, road reconstruction or road construction waste and vehicle sound .As considerable use of natural aggregates for road construction that makes, the increasing amount of solid waste that makes attention of many researchers in the pigment industries in innovate the feasibility of the application of RCA in Asphalt mixture. construction and demolition wastes, including recycle construction aggregate RCA constitute a major part of municipal solid waste by using RCA in Asphalt gives the significant economic and environmental benefits. However, in spite of such promising potentials, insufficient and inconclusive data and information of the engineering properties of RCA had limited liability and design specifications of RCA. This laboratory investigation included the measurement of RCA strength, particle shape, water absorption, crushing value, weak particles, wet and dry strength variation and particle density. Also porous Asphalt pavements are design for dual duty, As they provide payments for parking and roads and also serve as storm water storage and in filtration system. They are in demand because they offers site planners and public works officials the opportunity to manage storm water in an environmentally friendly way [it makes cost effective attractive parking lots long lifespan\} improve water quality.
\end{abstract}

\section{INTRODUCTION}

As the population of world are continuously increasing day by day with an expanding world, the demand or necessity for extensive Road networks. As available natural resources become scare use of recycled material for construction, including payments construction over the past decades, increasing in the application of waste materials in different layers of flexible pavement including Asphalt surface layer base layer now what is so many waste material suggest plastics tyres glasses are used for construction of flexible pavement Asphalt surface place on fundamental role in flexible payment system. as it is real or with stand varying traffic loads environmental conditions.

The Asphalt surface is critical for safe and comfortable driving use of solid waste in Asphalt reduced not only environment is associated with waste disposal but also the demand for Asphalt binder and the course and aggregate fine which may result cost saving and economic advantages. The uses of recycled materials in external surface layer can contribute to further improvement of engineering characteristics of Asphalt pavement materials as well as payment performance, representing the value of added solid waste, the selection of waste materials to be used for pavement construction particularly Asphalt surface layer is of importance is the use of waste material should not adversely affect on the structure and functional aspects of the Pavement. The porous pavement is a storm water drainage system which allows rainwater and runoff to make through the payments eventually seeping into the underlying soil. permeable pavement in beneficial to the environment because it reduce storm water volume treat the storm water quality, and replenish the ground water supply and lower air temperatures on hot days. Asphalt pavements with stone reservoirs are a multifunctional low impact development LID technique. this is integrates ecological and environmental goals for a site with land development goals decreases the net environmental impact for a project, they not only provides strong Pavement surface for parking, walking trials and Roads they were designed to treat storm water runoff.

this paper presents the results of an experiment component research for designing Asphalt mixtures for designing Asphalt mixtures involves the process of selecting suitable for proper ingredient, filler, binder, etc. 


\section{LITERATURE REVIEW}

A) Performance of pavement can be generally defined as to the change in their condition or function with respect to age. It can also be indicative of the ability of a pavement to carry the intended traffic and satisfy the environment during the design life, both functionally and structurally. With the increased economic and development activities in India, the traffic has increased multi fold during the last 3 decades resulting in the overstressing of road network. The development of higher stresses leads to performance failure of the pavements. If the pavements fail to carry the design loads satisfactorily, then the failure is of structural type. It is of functional type, if the pavement does not provide a smooth riding surface. The uneven surface not only causes discomfort, but also increases the Vehicle Operating Cost (VOC), thus influencing the overall transportation cost. This chapter gives a broad outline of the importance of pavement performance evaluation, type of models, applications of performance models in other countries for their Pavement Management System and the research studies carried out so Far.

B) The tyre is a complex and high-tech safety product representing a century of manufacturing innovation, which is still on-going. From the material point of view the tyre is made up of three main components materials: (i) elastomeric compound, (ii) fabric and (iii) steel. The fabric and steel form the structural skeleton of the tyre with the rubber forming the "flesh" of the tyre in the tread, side wall, apexes, liner and shoulder wedge. This engineering process is necessary to transform natural rubber in a product able to ensure performance, durability and safety. In fact, natural rubber is sticky in nature and can easily deform when heated up and it is brittle when cooled down. In this state it cannot be used to make products with a good level of elasticity. The reason for inelastic deformation of not-vulcanised rubber can be found in the chemical nature as rubber is made of long polymer chains. These polymer chains can move independently relative to each other, and this will result in a change of shape. By the process of vulcanisation cross-links are formed between the polymer chains, so the chains cannot move independently anymore. As a result, when stress is applied the vulcanised rubber will deform, but upon release of the stress the rubber article will go back to its original shape. Compounding is finally used to improve the physical properties of rubber by incorporating the ingredients and ancillary substances necessary for vulcanisation, but also to adjust the hardness and modulus of the vulcanised product to meet the end requirement. Different substances can be added according to the different tyre mixtures; these include mineral oil and reinforcing fillers as carbon black and silica. In general, truck TR contains larger percentages of natural rubber compared to that from car . the general tyre composition of tyres used in cars and trucks in the EU.

C) Porous asphalt pavements are typically recommended for parking areas and low-volume roadways. Additional applications of porous asphalt are for pedestrian walkways, sidewalks, driveways, bike lanes, and shoulders (Hein et al. 2013). Also, porous asphalt pavements have been used successfully for residential and urban streets, as well as highways. Porous asphalt pavements can be installed as whole or in part with traditional impervious asphalt.

D) pavements. When installed in combination with impervious pavements or adjacent to building roofs, porous asphalt can sufficiently contain and treat the additional runoff generated.

E) Porous asphalt pavements are an alternative Technology that differs from traditional Asphalt pavement designs in that the structure permits fluids to pass freely really through it, reducing or controlling the amount of runoff from the surrounding area, by allowing precipitation and runoff to flow through the structure this payment type functions are as additional storm water management technique accounting from groundwater recharge both includes improve Stormwater management improve skid resistance production of spray two drivers and pedestrians as well as a potential noise reduction.

\section{TESTING METHODS}

The water absorbing capacity, water retention capacity and compressive strength of hard and water retentive motor liquidity of the fresh mortar as well as the rutting resistances, moisture susceptibility low-temperature bending résistance surface slip resistance and cooling effect of water retentive Asphalt concrete where tested using at least three replicate specimen.

\section{Objective:-}

1) to study of porous pavement.

2) Planning and designing of porous pavement.

3) Environmental consideration of porous Asphalt.

4) Development of permeable pavement.

\section{ENVIRONMENT BENEFITS}

-Reduce the surface runoff of the storm water

-Pervious concrete pavement reduces or eliminates runoff and permits natural treatment of runoff water 
-By collecting rainfall and allowing it to infiltrate, groundwater, aquifer recharge, water table level is increased

-Pervious concrete is a lightweight pavement material

-Effective utilization of waste material such as fly ash makes this technique more eco- friendly

-Pervious concrete pavement is ideal for protecting trees in a paved environment.

-Although high-traffic pavements are not a typical use for pervious concrete, concrete surfaces also can improve safety during rain.

\section{CONCLUSION}

1)This this paper concludes that the high linear or correlation of the the values of porous asphalt means the project is precise and accurate.

2)Design maintenance and water quality control aspects relevant to the practitioner wear out lined for permeable and porous pavement system. the most important target pollutants where hydrocarbon, heavy metals and nutrients.

3)Recent innovations where highlighted and explained and their potential for further research work was outlined. The development of a combined geothermal heating and cooling water treatment and recycling payment system is promising and therefore in coverage fourther work on the assumptions of self-sustainability encouraged.

4)The resilient modulus of unbound materials is an important property used for pavement design recycled materials, such as RAP, may exhibit unique properties due to the existence of Asphalt. this study examine the effect of RAP percentage on the resilient modulus of base materials. A constant head permanent was selected for conducting permeability test for specimens containing RAP as the base for materials.

\section{REFERENCES}

[1] Dr B V Kiran Kumar, Manjunatha S, Shiva Prasad N. "Porous asphalt pavement a tentative mix design guideline" new generation open graded friction course approach

[2] Recycling of Asphalt Pavement. Missouri Asphalt Pavement Associa-tion, Jefferson City. http://www.moasphalt.org/facts/environmental/recycling.htm. Accessed July 26, 2010.

[3] McGarrah, E. J. Evaluation of Current Practices of Reclaimed Asphalt Pavement/Virgin Aggregate as Base Course Material. MS dissertation. University of Washington, Seattle, 2007.

[4] Cahill, T.H., M. Adams, \& C. Marm(2005). Stormwater Management with Porous Pavements. Government Engineering, March-April, pp. 14-19.

[5] CTC \& Associates Inc. (2012). Porous Asphalt Performance in Cold Regions. Report 2012-12TS. Minnesota Department of Transportation, St. Paul, Minn.

[6] Moriyoshi, A.; Jin, T.; Nakai, T.; Ishikawa, H. Evaluation methods for porous asphalt pavement in service for fourteen years. Constr. Build. Mater. 2013.

[7] Ma, X.; Liu, J.; Wu, Z.; Shi, C. Effects of SAP on the properties and pore structure of high performance cement-based materials. Constr. Build. Mater. 2017

[8] Nakayama, T.; Shizuka, H. Study on pavement performance of porous asphalt pavement withwater saving and cooling. Constr. Build. Mater. 2015.

[9] Shen, P. Development and Performance Evaluation of WaterRetaining Cement Mortar in Semi-Flexible Pavement with Wate Retention and Cooling; Chongqing Jiaotong University of China: Chongqing, China, 2012. 